\title{
Influence of 3D-CRT and conformal IMRT on thyroid function of patients with cervical and upper thoracic esophageal cancer and comparison of clinical efficacy
}

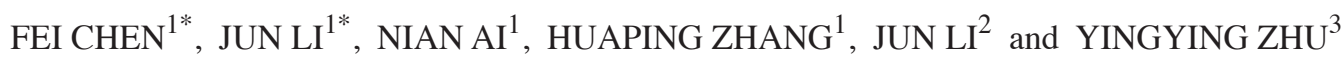 \\ ${ }^{1}$ Department of Oncology, Xiaogan Hospital Affiliated to Wuhan University of Science and Technology; \\ ${ }^{2}$ Department of Oncology, The Central Hospital of Xiaogan, Xiaogan, Hubei 432000; \\ ${ }^{3}$ Cancer Center, Huazhong University of Science Technology Tongji Hospital, \\ Sino-French New City Branch, Wuhan, Hubei 430100, P.R. China
}

Received July 25, 2018; Accepted January 17, 2019

DOI: $10.3892 /$ ol.2019.9989

\begin{abstract}
Clinical efficacy in patients with cervical and upper thoracic esophageal cancer was compared between three-dimensional conformal radiotherapy (3D-CRT) and conformal intensity-modulated radiotherapy (IMRT). Medical data of 120 esophageal cancer patients undergoing RT in the Radiology Department in Xiaogan Hospital Affiliated to Wuhan University of Science and Technology (Xiaogan, China) from March 2015 to March 2018 were retrospectively analyzed. Patients were divided into 3D-CRT group (treated with 3D-CRT, n=60) and IMRT group (treated with IMRT, $\mathrm{n}=60)$. The target conformal index (CI), PTV maximum dose $\left(\mathrm{D}_{\max }\right)$, PTV $\mathrm{D}_{\text {min }}$ and PTV $\mathrm{D}_{\text {mean }}$ in both groups were observed. Changes in double-lung V5, double-lung V20, double-lung V30 and spinal cord $\mathrm{D}_{\max }$ in both groups were also observed. The serum free triiodothyronine (FT3), free tetraiodothyronine (FT4) and thyroid-stimulating hormone (TSH) concentrations were detected via chemiluminescence assay. Moreover, the short-term efficacy and radiation injury were observed. CI in IMRT group was significantly higher than that in 3D-CRT group $(\mathrm{P}<0.001)$. The organ-at-risk dose
\end{abstract}

Correspondence to: Dr Jun Li, Department of Oncology, The Central Hospital of Xiaogan, 6 Guangchang Road, Xiaogan, Hubei 432000, P.R. China

E-mail: pj84jd@163.com

Dr Yingying Zhu, Cancer Center, Huazhong University of Science Technology Tongji Hospital, Sino-French New City Branch, 288 Xintian Street, Wuhan, Hubei 430100, P.R. China

E-mail: julianzyy@hotmail.com

*Contributed equally

Key words: cervical and upper thoracic esophageal cancer, threedimensional conformal radiotherapy, conformal intensity-modulated radiotherapy, target conformal index, double-lung V20, thyroid function parameter V20 in IMRT group was obviously lower than that in 3D-CRT group $(\mathrm{P}<0.001)$. Serum FT3 and FT4 concentrations in both groups before RT were significantly higher than those after RT $(\mathrm{P}<0.05)$, but the TSH concentration was significantly lower than that after RT $(\mathrm{P}<0.05)$. Serum FT3 and FT4 concentrations in IMRT group after RT were obviously higher than those in 3D-CRT group $(\mathrm{P}<0.05)$. The incidence rates of radiation esophagitis and radiation pneumonitis in IMRT group were remarkably lower than those in 3D-CRT group $(\mathrm{P}<0.05)$. IMRT can reduce the double-lung V20 in patients, improve the target conformal degree, better protect the normal tissues, cause less damage to thyroid function, and reduce radiation injury during and after RT of esophageal cancer.

\section{Introduction}

Esophageal cancer is one of the frequently-occurring malignant tumors in human, whose incidence rate shows an increasing trend year by year with a higher mortality rate (1). Clinical therapeutic methods of esophageal cancer mainly include surgery, chemotherapy, biotherapy and radiotherapy (RT). However, the overall therapeutic effect is still unsatisfactory, and the 5-year survival rate of patients with advanced esophageal cancer is only approximately $25 \%$ (2). Surgical resection dominated in the treatment of esophageal cancer in the past, but the risk of surgical resection is high due to the adjacent location of tumor to great vessels in patients with cervical and upper thoracic esophageal cancer. To ensure the safe boundary in surgery, total laryngectomy often needs to be performed, seriously affecting postoperative life and quality of life of patients (3). With the development of medical technology, RT has been gradually applied in the treatment of esophageal cancer. RT can inhibit and kill tumor cells through different rays and reduce the volume of tumor lesions, which has a comparable therapeutic effect to surgical treatment but a lower risk of complications in patients than surgical treatment (4). The radiation target area of patients with cervical and upper thoracic esophageal cancer is fixed, and the range of motion is smaller, thus RT is a preferred local treatment means for such patients (5). During RT, tumor tissues and 
normal tissues are exposed to ionizing radiation, in which tumor tissues are treated with radioactive rays and normal tissues are damaged, and a series of adverse reactions, such as thyroid dysfunction, radiation-induced pulmonary injury and radiation esophagitis, can be caused $(6,7)$. Therefore, improving the RT effect on tumor and reducing the occurrence of complications are problems to be solved in the RT of esophageal cancer. In this study, patients with cervical and upper thoracic esophageal cancer were treated with three-dimensional conformal RT (3D-CRT) and conformal intensity-modulated RT (IMRT), and the dose, organ-at-risk dose, influence on thyroid function, clinical efficacy and radiation injury of the two different RT methods in esophageal cancer patients were investigated.

\section{Patients and methods}

General data. Medical data of 120 esophageal cancer patients undergoing RT in the Radiology Department in Xiaogan Hospital Affiliated to Wuhan University of Science and Technology (Xiaogan, China) from March 2015 to March 2018 were retrospectively analyzed. Patients were divided into 3D-CRT group (treated with 3D-CRT, $n=60$ ) and IMRT group (treated with IMRT, $n=60$ ). In 3D-CRT group, there were 39 males and 21 females aged 38-70 years with an average age of 55.62 \pm 6.47 years. In terms of tumor-node-metastasis (TNM) stage, there were 22 cases in T1N0M0, 23 cases in T2N0M0, 8 cases in T3NOM0 and 7 cases in T4NOM0. The length of lesions under the gastroscope was $4.5 \pm 1.3 \mathrm{~cm}$. In IMRT group, there were 43 males and 17 females aged 40-69 years with an average age of $53.75 \pm 7.08$ years. In terms of TNM stage, there were 19 cases in T1N0M0, 21 cases in T2N0M0, 11 cases in T3N0M0 and 9 cases in T4NOM0. The length of lesions under the gastroscope was $4.7 \pm 1.5 \mathrm{~cm}$.

Inclusion and exclusion criteria. Inclusion criteria: i) Patients diagnosed with cervical and upper thoracic esophageal cancer via pathological histology $(8)$, ii) patients receiving TNM staging according to the Clinical Staging Criteria for Non-Surgical Esophageal Cancer (9), iii) patients with the Karnofsky performance status (KPS) score $\geq 70$ points, iv) patients undergoing RT due to low possibility of surgical resection, and v) patients with complete clinicopathological data. Exclusion criteria: i) Patients complicated with other connective tissue diseases or metabolic endocrine diseases, ii) patients complicated with severe hepatic or renal dysfunction, iii) patients with a family history of mental disease or psychosis, or iv) patients with distant metastasis definitely confirmed by imaging examination. This study was approved by the Ethics Committee of Xiaogan Hospital Affiliated to Wuhan University of Science and Technology, and the patients and their family members were informed and signed the informed consent.

Treatment methods. Patients in 3D-CRT group were treated with 3D-CRT as follows (10): After simulated position using intravenous enhanced computed tomography (CT) (Hefei Meyer Photoelectric Technology Co., Ltd., Hefei, China), patients were fixed with thermoplastic film in a supine position, and data obtained by CT scanning were transmitted to


Figure 1. Comparison of PTV dose parameters between 3D-CRT group and IMRT group. (A-C) There was no significant difference in PTV $\mathrm{D}_{\max }$, PTV $D_{\text {min }}$, PTV $D_{\text {mean }}$ between 3D-CRT group and IMRT group $(\mathrm{P}>0.05)$. (D) CI in IMRT group was significantly higher than that in 3D-CRT group ( $\mathrm{t}=9.230, \mathrm{P}<0.001) .{ }^{*} \mathrm{P}<0.001$ compared with $3 \mathrm{D}-\mathrm{CRT}$ group. $\mathrm{PTV}$, planning target volume; 3D-CRT, three-dimensional conformal radiotherapy; IMRT, intensity-modulated radiotherapy; CI, conformal index.

the 3D-CRT planning system (Topslane Inc., Pleasant Hill, CA, USA) for three-dimensional reconstruction. The gross tumor volume (GTV, the volume of lymph nodes $\geq 1 \mathrm{~cm}$ and visible tumor), clinical target volume (CTV, uniform external expansion of GTV for 6-7 mm, including superior mediastinal lymphatic drainage region and bilateral supraclavicular region) and planning target volume (PTV, including the scope and setup error of organ motion and CTV, namely external expansion of X-and Y-axis for $10 \mathrm{~mm}$ and $\mathrm{Z}$-axis for $15 \mathrm{~mm}$ based on CTV with the geometric center of GTV as radiation field center) were delineated. In IMRT (11), GTV, CTV and PTV (external expansion of CTV for 6-7 $\mathrm{mm}$ along the threedimensional direction) were determined by the clinician, and isocenter irradiation was adopted using 3, 5, 7 and 9 coplanar non-through radiation fields in the treatment plan with the $360^{\circ}$ uniform distribution of gantry angle. The prescribed dose of PTV was 60 Gy (2 Gy/time, 5 times/week, a total of 30 times), and the treatment lasted for 6 weeks. The organ-at-risk dose: double-lung V5 $\leq 50 \%$, V $20 \leq 30 \%$, V $30 \leq 20 \%$, and spinal cord $\mathrm{D}_{\max } \leq 45 \mathrm{~Gy}$.

Observation indexes. The target conformal index (CI) (12), PTV maximum dose $\left(\mathrm{D}_{\max }\right)$, PTV $\mathrm{D}_{\min }$ and PTV $\mathrm{D}_{\text {mean }}$ in both groups were observed. The organ-at-risk dose in RT: Changes in double-lung V5, double-lung V20, double-lung V30 and spinal cord $D_{\max }$ in both groups were observed. The percentage of volume of lung exposed to 5, 20 and 30 Gy 
Table I. Baseline data in 3D-CRT group and IMRT group [n (\%)]/mean \pm SD.

\begin{tabular}{|c|c|c|c|c|}
\hline Factors & 3D-CRT group $(\mathrm{n}=60)$ & IMRT group $(n=60)$ & $\mathrm{t} / \chi^{2}$ value & P-value \\
\hline Sex & & & 0.616 & 0.556 \\
\hline Male & $39(65.00)$ & $43(71.67)$ & & \\
\hline Female & $21(35.00)$ & $17(28.33)$ & & \\
\hline Age (years) & $55.62 \pm 6.47$ & $53.75 \pm 7.08$ & 1.510 & 0.133 \\
\hline Height $(\mathrm{cm})$ & $166.47 \pm 8.63$ & $164.22 \pm 6.75$ & 1.591 & 0.114 \\
\hline Weight (kg) & $61.31 \pm 10.65$ & $59.24 \pm 12.51$ & 0.975 & 0.331 \\
\hline Smoking history & & & 0.307 & 0.712 \\
\hline Yes & $33(55.00)$ & $36(60.00)$ & & \\
\hline No & $27(45.00)$ & $24(40.00)$ & & \\
\hline Tumor location & & & 0.481 & 0.923 \\
\hline Cervical segment & $7(11.67)$ & $5(8.33)$ & & \\
\hline Upper thoracic segment & $14(23.33)$ & $13(21.67)$ & & \\
\hline Middle thoracic segment & $26(43.33)$ & $28(46.67)$ & & \\
\hline Lower thoracic segment & $13(21.67)$ & $14(23.33)$ & & \\
\hline TNM stage & & & 1.034 & 0.792 \\
\hline T1N0M0 & $22(36.67)$ & $19(31.67)$ & & \\
\hline T2N0M0 & $23(38.33)$ & $21(35.00)$ & & \\
\hline T3N0M0 & $8(13.33)$ & $11(18.33)$ & & \\
\hline T4NOM0 & $7(11.67)$ & $9(15.00)$ & & \\
\hline $\begin{array}{l}\text { Lesion length under the } \\
\text { gastroscope }(\mathrm{cm})\end{array}$ & $4.5 \pm 1.3$ & $4.7 \pm 1.5$ & 0.780 & 0.436 \\
\hline
\end{tabular}

3D-CRT, three-dimensional conformal radiotherapy; IMRT, intensity-modulated radiotherapy; TNM, tumor-node-metastasis.

in the total volume of lung indicated the double-lung V5, V20 and V30. The serum free triiodothyronine (FT3), free tetraiodothyronine (FT4) and thyroid-stimulating hormone (TSH) concentrations in both groups before and after RT were detected using Centaur-XP full-automatic chemiluminescence immune analyzer (Siemens AG, Munich, Germany). FT3, FT4 and TSH kits (chemiluminescence assay) were purchased from Shanghai Xinyu Biotechnology Co., Ltd., Shanghai, China.

Short-term efficacy and radiation injury. Short-term efficacy: At 3 weeks after RT, the reduction of target tumor was evaluated via chest $\mathrm{CT}$, and the upper wall thickness $>5 \mathrm{~mm}$ in $\mathrm{CT}$ indicated the abnormality. The clinical efficacy was evaluated according to the response evaluation criteria in solid tumors of the World Health Organization (WHO) (13): complete response (CR), partial response (PR), stable disease (SD) and progressive disease $(P D)$, clinical response rate $(R R)=(C R+P R) /$ total cases $\mathrm{x} 100 \%$. Radiation injury: The radiation esophagitis and radiation pneumonitis were observed from 1 day after the start of RT to 3 months after the end of RT, and evaluated via radiation therapy oncology group (RTOG) criteria (14).

Statistical analysis. Statistical Product and Service Solutions (SPSS) 19.0 (Bizinsight, Beijing, China) was used for statistical analysis. Measurement data were expressed as mean \pm standard deviation. t-test was used for the intergroup comparison of measurement data, paired t-test was used for the intragroup comparison before and after treatment, and Chi-square test $\left(\chi^{2}\right)$ was adopted for the intergroup comparison of enumeration data. $\mathrm{P}<0.05$ was considered to indicate a statistically significant difference.

\section{Results}

Baseline data. There were no statistically significant differences in clinical baseline data, such as sex, age, height, weight, smoking history, tumor location, TNM stage and lesion length under the gastroscope, between 3D-CRT group and IMRT group $(\mathrm{P}>0.05)$ (Table I).

PTV dose parameters. The PTV $\mathrm{D}_{\max }, \mathrm{PTV} \mathrm{D}_{\min }, \mathrm{PTV}_{\text {mean }}$ and CI were 6813.41 $225.74 \mathrm{cGy}, 5054.31 \pm 193.52 \mathrm{cGy}$, $6257.35 \pm 216.25 \mathrm{cGy}$ and $0.605 \pm 0.063$ in 3D-CRT group, and $6737.07 \pm 267.36 \mathrm{cGy}, 5107.48 \pm 173.52 \mathrm{cGy}, 6199.07 \pm 195.26 \mathrm{cGy}$ and $0.719 \pm 0.072$ in IMRT group. There were no significant differences in PTV $\mathrm{D}_{\max }, \mathrm{PTV}_{\min }$ and PTV $\mathrm{D}_{\text {mean }}$ between 3D-CRT group and IMRT group $(\mathrm{P}>0.05)$. CI in IMRT group was significantly higher than that in $3 \mathrm{D}-\mathrm{CRT}$ group $(\mathrm{t}=9.230$, $\mathrm{P}<0.001$ ) (Fig. 1).

Organ-at-riskdose parameters. The organ-at-risk dose parameters V5, V20, V30 and spinal cord $\mathrm{D}_{\max }$ were $40.63 \pm 7.63 \%$, $25.63 \pm 2.57 \%, 18.52 \pm 1.93 \%$ and $4520.74 \pm 273.52 \mathrm{cGy}$ in 3D-CRT group, and $42.47 \pm 7.07 \%, 23.42 \pm 2.93 \%, 17.87 \pm 2.17 \%$ and $4481.63 \pm 237.12$ cGy in IMRT group. The organ-at-risk 

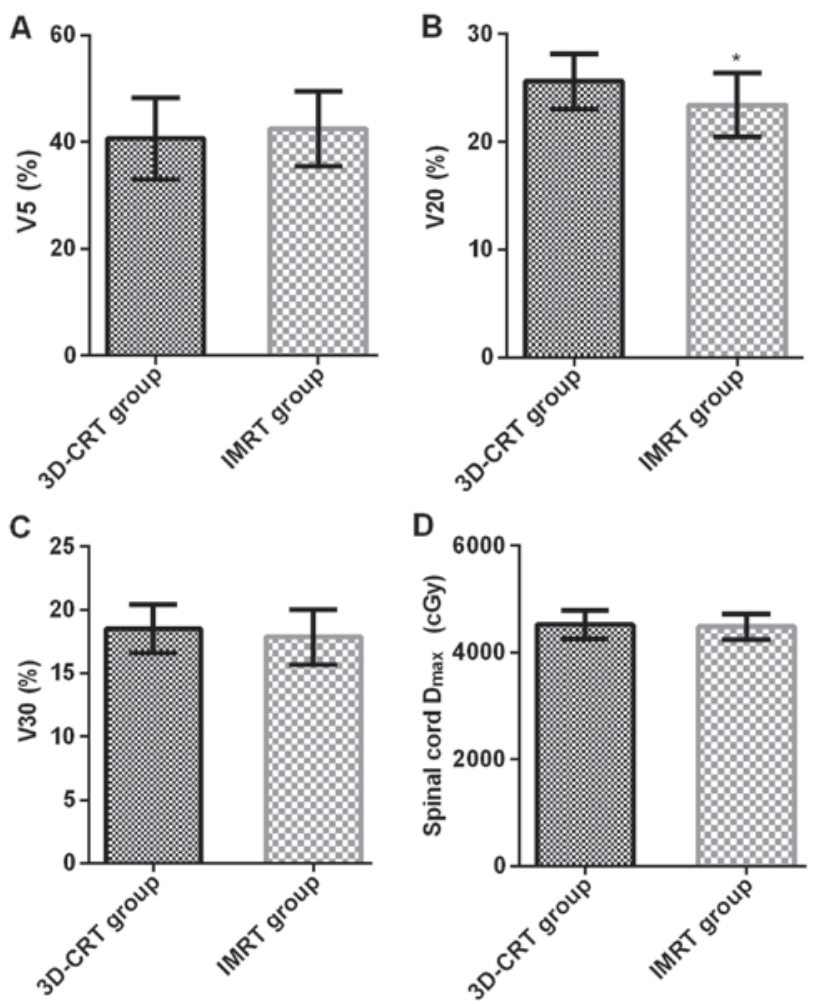

Figure 2. Comparison of PTV organ-at-risk dose parameters between 3D-CRT group and IMRT group. (A,C and D) Compared with IMRT group, the parameters of $\mathrm{V} 5, \mathrm{~V} 30$, and $\mathrm{D}_{\max }$ of spinal cord in 3D-CRT group showed no significant difference $(\mathrm{P}>0.05)$. (B) The risk parameter V20 in IMRT group was significantly lower than that in $3 \mathrm{D}-\mathrm{CRT}$ group $(\mathrm{t}=4.392, \mathrm{P}<0.001)$. ${ }^{*} \mathrm{P}<0.001$ compared with 3D-CRT group. PTV, planning target volume; 3D-CRT, three-dimensional conformal radiotherapy; IMRT, intensitymodulated radiotherapy.

dose parameters (V5 and V30) and spinal cord $\mathrm{D}_{\max }$ had no significant differences in 3D-CRT group compared with those in IMRT group $(\mathrm{P}>0.05)$. The organ-at-risk dose parameter V20 in IMRT group was obviously lower than that in 3D-CRT group $(\mathrm{t}=4.392, \mathrm{P}<0.001)$ (Fig. 2).

Changes in serum FT3, FT4 and TSH concentrations before and after RT. In 3D-CRT group, the serum FT3, FT4 and TSH concentrations were $5.73 \pm 2.25 \mathrm{nmol} / 1,11.93 \pm 4.11 \mathrm{nmol} / 1$ and $3.87 \pm 1.43 \mathrm{mIU} / 1$ before RT, and $4.13 \pm 1.75 \mathrm{nmol} / 1$, $8.59 \pm 2.73 \mathrm{nmol} / 1$ and $5.41 \pm 2.93 \mathrm{mIU} / 1$ after RT. In IMRT group, the serum FT3, FT4 and TSH concentrations were $5.77 \pm 2.31 \mathrm{nmol} / 1,12.26 \pm 4.27 \mathrm{nmol} / 1$ and $3.73 \pm 1.48 \mathrm{mIU} / 1$ before RT, and $4.91 \pm 2.03 \mathrm{nmol} / 1,9.73 \pm 3.37 \mathrm{nmol} / 1$ and $4.49 \pm 2.03 \mathrm{mIU} / 1$ after RT. There were no significant differences in serum FT3, FT4 and TSH concentrations in 3D-CRT group before RT compared with those in IMRT group $(\mathrm{P}>0.05)$. Serum FT3 and FT4 concentrations in 3D-CRT group before RT were significantly higher than those after RT $(\mathrm{t}=4.348$, $\mathrm{P}<0.001 ; \mathrm{t}=5.243, \mathrm{P}<0.001$ ), but the TSH concentration was significantly lower than that after $\mathrm{RT}(\mathrm{t}=3.659, \mathrm{P}<0.001)$. Serum FT3 and FT4 concentrations in IMRT group before RT were significantly higher than those after $\mathrm{RT}(\mathrm{t}=2.166, \mathrm{P}=0.032$; $\mathrm{t}=3.745, \mathrm{P}<0.001$ ), but the TSH concentration was significantly lower than that after RT $(\mathrm{t}=2.343, \mathrm{P}=0.020)$. Serum FT3 and FT4 concentrations in IMRT group after RT were obviously
Table II. Short-term clinical efficacy in 3D-CRT group and IMRT group [n (\%)].

\begin{tabular}{lcccc}
\hline Type & $\begin{array}{c}\text { 3D-CRT } \\
\text { group } \\
(\mathrm{n}=60)\end{array}$ & $\begin{array}{c}\text { IMRT } \\
\text { group } \\
(\mathrm{n}=60)\end{array}$ & $\chi^{2}$ value & P-value \\
\hline CR & $4(6.67)$ & $5(8.33)$ & - & - \\
PR & $49(81.67)$ & $51(85.00)$ & - & - \\
SD & $5(8.33)$ & $3(5.00)$ & - & - \\
PD & $2(3.33)$ & $1(1.67)$ & - & - \\
RR & $53(88.33)$ & $56(93.33)$ & 0.901 & 0.529 \\
\hline
\end{tabular}

3D-CRT, three-dimensional conformal radiotherapy; IMRT, intensitymodulated radiotherapy.

higher than those in 3D-CRT group $(\mathrm{t}=2.254, \mathrm{P}=0.026$; $\mathrm{t}=2.036, \mathrm{P}=0.044)$, but the TSH concentration was obviously lower than that in 3D-CRT group ( $\mathrm{t}=1.999, \mathrm{P}=0.047)$ (Fig. 3).

Short-term clinical efficacy and radiation injury. RR was $88.33 \%$ in 3D-CRT group and $93.33 \%$ in IMRT group. No significant difference was found in RR between 3D-CRT group and IMRT group $(\mathrm{P}>0.05)$ (Table II). The total incidence rates of radiation esophagitis and radiation pneumonitis were $65.00 \%$ and $40.00 \%$, respectively, in 3D-CRT group, and $28.33 \%$ and $20.00 \%$, respectively, in IMRT group. The incidence rates of radiation esophagitis and radiation pneumonitis in IMRT group were remarkably lower than those in 3D-CRT group $\left(\chi^{2}=16.205, \mathrm{P}<0.001 ; \chi^{2}=5.714\right.$, $\mathrm{P}=0.028$ ) (Table III).

\section{Discussion}

Esophageal cancer is a malignant parenchymal tumor in the human esophagus, whose incidence rate has gradually increased in recent years and mortality rate is among the worst in human malignant tumors, and male patients are in the majority (15). The major clinical manifestations of esophageal cancer are cough, chest pain, chest distress, hemoptysis and difficulty in swallowing, and even dyspnea in severe cases. Esophageal cancer develops rapidly and can metastasize to adjacent organs or distant organs, leading to organ failure and seriously threatening the life of patients (16). Radical resection of esophageal cancer is a major therapeutic method for esophageal cancer. However, the surgical incision is large, and the chest cavity is exposed for a long time during surgery, so the lungs are prone to infection and compression, and the lung function is affected easily, producing an unsatisfactory surgical effect (17).

RT kills cancer cells on the radioactive beam using the energetic particles, which can remove residual tumor cells at the pathogenic site to the maximum degree, and reduce metastasis and recurrence rates with a comparable effect to surgical treatment (5). However, normal cells can also be killed while tumor cells are killed during RT. Therefore, the improvement of RT lies in increasing the therapeutic gain ratio, and controlling the radiation dose in the target 



Figure 3. Comparison of serum FT3, FT4 and TSH concentrations between 3D-CRT group and IMRT group before and after radiotherapy. No significant difference in serum (A) FT3, (B) FT4 and (C) TSH concentrations between 3D-CRT group and IMRT group before radiotherapy (P>0.05). (A and B) Serum FT3 and FT4 concentrations in 3D-CRT and IMRT groups before radiotherapy were significantly higher than those after radiotherapy $(\mathrm{t}=4.348, \mathrm{P}<0.001 ; \mathrm{t}=5.243$, $\mathrm{P}<0.001, \mathrm{t}=2.166, \mathrm{P}=0.032 ; \mathrm{t}=3.745, \mathrm{P}<0.001)$. Serum FT3 and FT4 concentrations in 3D-CRT group were significantly higher than those IMRT after RT $(\mathrm{t}=2.254, \mathrm{P}=0.026 ; \mathrm{t}=2.036, \mathrm{P}=0.044)$. (C) TSH concentration in 3D-CRT group before RT, IMRT group before RT, 3D-CRT group after RT were signifiaantly lower than that after radiotherapy $\mathrm{t}=3.659, \mathrm{P}<0.001, \mathrm{t}=2.343, \mathrm{P}=0.020$ ). TSH concentration was obviously lower in IMRT group than that in $3 \mathrm{D}-\mathrm{CRT}$ group $(\mathrm{t}=1.999, \mathrm{P}=0.047) .{ }^{*} \mathrm{P}<0.05$ compared with before chemotherapy; ${ }^{\sharp \mathrm{P}}<0.05$ compared with the post-chemotherapy IMRT group. FT3, free triiodothyronine; FT4, free tetraiodothyronine; TSH, thyroid-stimulating hormone; 3D-CRT, three-dimensional conformal radiotherapy; IMRT, intensity-modulated radiotherapy.

Table III. Comparison of incidence rate of acute radiation injury between 3D-CRT group and IMRT group [n (\%)].

\begin{tabular}{|c|c|c|c|c|}
\hline Type & 3D-CRT group $(\mathrm{n}=60)$ & IMRT group $(n=60)$ & $\chi^{2}$ value & P-value \\
\hline \multicolumn{5}{|l|}{ Radiation esophagitis } \\
\hline Grade I & $7(11.67)$ & $4(6.67)$ & 0.901 & 0.529 \\
\hline Grade II & $25(41.67)$ & $10(16.67)$ & 9.076 & 0.005 \\
\hline Grade III & $7(11.67)$ & $3(5.00)$ & 1.745 & 0.322 \\
\hline Total incidence rate & $39(65.00)$ & $17(28.33)$ & 16.205 & $<0.001$ \\
\hline \multicolumn{5}{|l|}{ Radiation pneumonitis } \\
\hline Grade I & $9(15.00)$ & $6(10.00)$ & 0.686 & 0.582 \\
\hline Grade II & $13(21.67)$ & $5(8.33)$ & 4.183 & 0.071 \\
\hline Grade III & $2(3.33)$ & $1(1.67)$ & 0.342 & 0.909 \\
\hline Total incidence rate & $24(40.00)$ & $12(20.00)$ & 5.714 & 0.028 \\
\hline
\end{tabular}

3D-CRT, three-dimensional conformal radiotherapy; IMRT, intensity-modulated radiotherapy.

area and lesion area as far as possible, so that tumor cells can be better killed and the damage to adjacent normal organs is reduced (18). 3D-CRT is a mainstream technique in the clinical RT of malignant tumors, which, as a physical measure, can distribute the dose evenly in the threedimensional target area. From the perspective of radiation, the shape of target area is similar to the distribution shape of high-dose area, and the dose output rate in the radiation area can be determined based on the actual requirements (19). In IMRT, the photon beam aims at and concentrates on the target area from different directions, the three-dimensional shape in the high-dose target area is consistent, the scope of surrounding tissues radiated is reduced and the unnecessary dose is also reduced, thus lowering the damage rate of surrounding tissues (20). In this study, RR was $88.33 \%$ in 3D-CRT group and $93.33 \%$ in IMRT group, and there was no significant difference between the two groups, indicating that both 3D-CRT and IMRT can effectively kill cancer cells and improve the short-term efficacy on patients with esophageal cancer. The above results are similar to the study of Grills et al (21) that 3D-CRT and IMRT have good clinical efficacy on patients with inoperable non-small cell lung cancer.

Radiation-induced pulmonary injury and radiation esophagitis are major factors limiting the RT dose of thoracic tumors (22). The overall survival of patients with esophageal cancer is significantly prolonged with the application of multiple therapeutic methods, but radiation-induced pulmonary injury and radiation esophagitis are important reasons affecting the quality of life of patients, which can offset the benefits of RT. It was found in a prospective study of RTOG that radiation-induced pulmonary injury has a close correlation with the double-lung V20. The higher the double-lung V20 is, the more severe the radiation-induced pulmonary injury will 
be (23). In this study, CI in IMRT group was significantly higher than that in 3D-CRT group, the organ-at-risk dose parameter V20 in IMRT group was obviously lower than that in 3D-CRT group, and the incidence rates of radiation esophagitis and radiation pneumonitis in IMRT group were obviously lower than those in 3D-CRT group, suggesting that IMRT can reduce the double-lung V20 in patients, improve the target conformal degree, better protect the normal tissues and reduce the adverse reactions during and after RT of esophageal cancer. According to the study of Yom et al (24), in advanced NSCLC patients with chemoradiotherapy, the risk of $\geq$ grade 3 treatment-related pneumonia caused by IMRT is significantly lower than that caused by 3D-CRT, which is similar to the conclusion in this study.

During RT, the thyroid gland is in the radiation field, leading to radiation injury in the patient's thyroid gland, damaging the thyroid gland, causing hypothyroidism, and affecting the quality of life of patients (25). Nishiyama et al (19) argued that in the early stage of RT, the permeability of cell membrane of thyroid gland begins to increase after radiation, the level of thyroid hormone released into the blood also increases, and the pituitary gland is inhibited via negative feedback, thus reducing the level of TSH. After RT, there are changes in follicular cells in the thyroid gland, irreversible fibrosis and degeneration gradually occur and the permeability of cell membrane is also changed, so that levels of FT3 and FT4 begin to drop, increasing the level of TSH via negative feedback. Results of this study revealed that serum FT3 and FT4 concentrations in 3D-CRT group and IMRT group before RT were significantly higher than those after RT, but the concentration of TSH was significantly lower than that after RT. Serum FT3 and FT4 concentrations in IMRT group after RT were obviously higher than those in 3D-CRT group, but the concentration of TSH was obviously lower than that in 3D-CRT group, indicating that RT will cause certain damage to the thyroid function, but such damage caused by IMRT is less. The possible reason is that IMRT increases the target conformal degree, decreases the radiation dose against surrounding normal tissues and reduces the thyroid function damage.

In this study, patients were screened strictly according to inclusion and exclusion criteria, and there were no statistically significant differences in clinical baseline data, such as sex, age, height, weight, smoking history, tumor location, TNM stage and lesion length under the gastroscope, between 3D-CRT group and IMRT group, thus ensuring the preciseness and reliability of the study. However, patients with esophageal cancer were not followed up for survival and prognosis after treatment with 3D-CRT and IMRT, and the survival time of patients was not clarified, so there were certain limitations. In future, the research time should be prolonged to observe the overall survival of esophageal cancer patients undergoing 3D-CRT and IMRT.

In conclusion, both 3D-CRT and IMRT can effectively kill cancer cells and improve the short-term efficacy on patients with esophageal cancer. IMRT can reduce the double-lung V20 in patients, improve the target conformal degree, better protect the normal tissues, cause less damage to thyroid function, and reduce radiation injury during and after RT of esophageal cancer.

\section{Acknowledgements}

Not applicable.

\section{Funding}

No funding was received.

\section{Availability of data and materials}

The datasets used and/or analyzed during the current study are available from the corresponding author on reasonable request.

\section{Authors' contributions}

FC drafted and revised the manuscript. FC and JL (second author) recorded and analyzed the general data of patients. NA, HZ and JL (fifth author) were responsible for observation indexes. FC and YZ assisted with short-term efficacy and radiation injury analysis, and contributed to the conception and design of the study. All authors read and approved the final manuscript.

\section{Ethics approval and consent to participate}

This study was approved by the Ethics Committee of Xiaogan Hospital Affiliated to Wuhan University of Science and Technology (Xiaogan, China). Patients who participated in this research had complete clinical data. Signed written informed consents were obtained from the patients or the guardians.

\section{Patient consent for publication}

Not applicable.

\section{Competing interests}

The authors declare that they have no competing interests.

\section{References}

1. Caudell JJ, Carroll WR, Spencer SA and Bonner JA: Examination of laryngoesophageal dysfunction-free survival as an endpoint in nonsurgical treatment of squamous cell carcinomas of the larynx and hypopharynx. Cancer 117: 4447-4451, 2011.

2. Pasquali S, Yim G, Vohra RS, Mocellin S, Nyanhongo D, Marriott P, Geh JI and Griffiths EA: Survival after neoadjuvant and adjuvant treatments compared to surgery alone for resectable esophageal carcinoma: A network meta-analysis. Ann Surg 265: 481-491, 2017.

3. Chen J, Su T, Lin Y, Wang B, Li J, Pan J and Chen C: Intensitymodulated radiotherapy combined with paclitaxel and platinum treatment regimens in locally advanced esophageal squamous cell carcinoma. Clin Transl Oncol 20: 411-419, 2018.

4. Wong AT, Shao M, Rineer J, Lee A, Schwartz D and Schreiber D: The impact of adjuvant postoperative radiation therapy and chemotherapy on survival after esophagectomy for esophageal carcinoma. Ann Surg 265: 1146-1151, 2017.

5. McDowell LJ, Huang SH, Xu W, Che J, Wong RKS, Brierley J, Kim J, Cummings B, Waldron J, Bayley A, et al: Effect of intensity modulated radiation therapy with concurrent chemotherapy on survival for patients with cervical esophageal carcinoma. Int $\mathbf{J}$ Radiat Oncol Biol Phys 98: 186-195, 2017.

6. Niezink AGH, de Jong RA, Muijs CT, Langendijk JA and Widder J: Pulmonary function changes after radiotherapy for lung or esophageal cancer: A systematic review focusing on dose-volume parameters. Oncologist 22: 1257-1264, 2017. 
7. Suntharalingam M, Winter K, Ilson D, Dicker AP, Kachnic L, Konski A, Chakravarthy AB, Anker CJ, Thakrar H, Horiba N, et al: Effect of the addition of cetuximab to paclitaxel, cisplatin, and radiation therapy for patients with esophageal cancer: The NRG oncology RTOG 0436 phase 3 randomized clinical trial. JAMA Oncol 3: 1520-1528, 2017.

8. Takeuchi M, Suda K, Hamamoto Y, Kato M, Mayanagi S, Yoshida K, Fukuda K, Nakamura R, Wada N, Kawakubo H, et al: Technical feasibility and oncologic safety of diagnostic endoscopic resection for superficial esophageal cancer. Gastrointest Endosc 88: 456-465, 2018.

9. Japanese Gastric Cancer Association: Japanese gastric cancer treatment guidelines 2010 (ver. 3). Gastric Cancer 14: 113-123, 2011.

10. Xu D, Li G, Li H and Jia F: Comparison of IMRT versus 3D-CRT in the treatment of esophagus cancer: A systematic review and meta-analysis. Medicine (Baltimore) 96: e7685, 2017.

11. Chen YJ, Liu A, Han C, Tsai PT, Schultheiss TE, Pezner RD, Vora N, Lim D, Shibata S, Kernstine KH, et al: Helical tomotherapy for radiotherapy in esophageal cancer: A preferred plan with better conformal target coverage and more homogeneous dose distribution. Med Dosim 32: 166-171, 2007.

12. Sun HT, Yang RJ, Jiang P, Jiang WJ, Li JN, Meng N and Wang JJ: Dosimetric analysis of volumetric modulated arc therapy and intensity modulated radiotherapy for patients undergone breastconserving operation. Beijing Da Xue Xue Bao Yi Xue Ban 50: 188-192, 2018 (In Chinese).

13. Subbiah V, Chuang HH, Gambhire D and Kairemo K: Defining clinical response criteria and early response criteria for precision oncology: Current state-of-the-art and future perspectives. Diagnostics (Basel) 7: 10, 2017.

14. Ali AN, Zhang P, Yung WKA, Chen Y, Movsas B, Urtasun RC Jones CU, Choi KN, Michalski JM, Fischbach AJ, et al: NRG oncology RTOG 9006: A phase III randomized trial of hyperfractionated radiotherapy (RT) and BCNU versus standard RT and BCNU for malignant glioma patients. J Neurooncol 137: 39-47, 2018.

15. Abraham JM and Meltzer SJ: Long noncoding RNAs in the pathogenesis of Barrett's esophagus and esophageal carcinoma. Gastroenterology 153: 27-34, 2017.

16. Muto M, Ohtsu A, Miyata Y, Shioyama Y, Boku N and Yoshida S Self-expandable metallic stents for patients with recurrent esophageal carcinoma after failure of primary chemoradiotherapy. Jpn J Clin Oncol 31: 270-274, 2001.

17. Liu S, Anfossi S, Qiu B, Zheng Y, Cai M, Fu J, Yang H, Liu Q, Chen Z, Fu J, et al: Prognostic factors for locoregional recurrence in patients with thoracic esophageal squamous cell carcinoma treated with radical two-field lymph node dissection: results from long-term follow-up. Ann Surg Oncol 24: 966-973, 2017.
18. Deng JY, Wang C, Shi XH, Jiang GL, Wang Y, Liu Y and Zhao KL: Reduced toxicity with three-dimensional conformal radiotherapy or intensity-modulated radiotherapy compared with conventional two-dimensional radiotherapy for esophageal squamous cell carcinoma: A secondary analysis of data from four prospective clinical trials. Dis Esophagus 29: 1121-1127, 2016.

19. Nishiyama K, Kozuka T, Higashihara T, Miyauchi K and Okagawa K: Acute radiation thyroiditis. Int J Radiat Oncol Biol Phys 36: 1221-1224, 1996.

20. Yang H, Feng C, Cai BN, Yang J, Liu HX and Ma L: Comparison of three-dimensional conformal radiation therapy, intensitymodulated radiation therapy, and volumetric-modulated arc therapy in the treatment of cervical esophageal carcinoma. Dis Esophagus 30: 1-8, 2017.

21. Grills IS, Yan D, Martinez AA, Vicini FA, Wong JW and Kestin LL: Potential for reduced toxicity and dose escalation in the treatment of inoperable non-small-cell lung cancer: A comparison of intensity-modulated radiation therapy (IMRT), $3 \mathrm{D}$ conformal radiation, and elective nodal irradiation. Int $\mathrm{J}$ Radiat Oncol Biol Phys 57: 875-890, 2003.

22. Kong FM, Ten Haken RK, Schipper M, Frey KA, Hayman J, Gross M, Ramnath N, Hassan KA, Matuszak M, Ritter T, et al: Effect of midtreatment PET/CT-adapted radiation therapy with concurrent chemotherapy in patients with locally advanced nonsmall-cell lung cancer: A phase 2 clinical trial. JAMA Oncol 3: 1358-1365, 2017.

23. Graham MV, Purdy JA, Emami B, Harms W, Bosch W, Lockett MA and Perez CA: Clinical dose-volume histogram analysis for pneumonitis after 3D treatment for non-small cell lung cancer (NSCLC). Int J Radiat Oncol Biol Phys 45: 323-329, 1999.

24. Yom SS, Liao Z, Liu HH, Tucker SL, Hu CS, Wei X, Wang X, Wang S, Mohan R, Cox JD, et al: Initial evaluation of treatmentrelated pneumonitis in advanced-stage non-small-cell lung cancer patients treated with concurrent chemotherapy and intensity-modulated radiotherapy. Int J Radiat Oncol Biol Phys 68: 94-102, 2007.

25. De Felice F, de Vincentiis M, Luzzi V, Magliulo G, Tombolini M, Ruoppolo G and Polimeni A: Late radiation-associated dysphagia in head and neck cancer patients: Evidence, research and management. Oral Oncol 77: 125-130, 2018.

This work is licensed under a Creative Commons Attribution-NonCommercial-NoDerivatives 4.0 International (CC BY-NC-ND 4.0) License. 